\title{
Axillary Neoplasm
}

National Cancer Institute

\section{Source}

National Cancer Institute. Axillary Neoplasm. NCI Thesaurus. Code C35749.

A benign or malignant neoplasm that affects the structures of the axilla. Representative examples include axillary lipoma, axillary lymph node lymphoma, and metastatic carcinoma to the axillary lymph nodes. 